\title{
Foreword: Bridging physical and socio-economic research in the Mediterranean basin
}

\section{Gérard Begni}

Political, industrial and commercial specific interests, as well as public opinions balanced within extreme sensitivities, most often obscure the debates about global change issues, consciously or not. There is a wide range of viewpoints on these issues, two extreme being to consider them as an abstract intellectual speculation without any day-to-day interest, or as a major threat to mankind, more or less related to metaphysical fears of a mythological final apocalypse. On other opposite sides, people feel either strongly motivated to act against adverse events, or consider them as a manifestation of an everlasting destiny. In addition, bona fide people tend to analyse such phenomena according to how much they remind them of a few years period change, a time scale in which significant long-term changes are quite obscured by natural interannual variability. Facing such rational or irrational debates, scientists have a major and unavoidable responsibility. Addressing global change issues over the longest possible period, including paleoclimates, and at least using the very detailed information collected in past decades from an authentic scientific point of view, is mandatory. According to basic ethical rules, it is absolutely necessary to analyse and underline basic hypotheses, qualify and, whenever possible, quantify uncertainties sources. This is a complex task, especially when regional levels such as the Mediterranean basin are taken into consideration.

The Mediterranean region is a transition area covering the Mediterranean Sea as such and land encompassing it, limited by deserts to the south and temperate areas to the north. It is characterised by contrasting variations in temperature and precipitation between winter and summer. Winters are cool and relatively wet, while summers are warm and dry. The climate is very variable on interannual to secular time frames, and prone to extremes. The ocean and land ecosystems are undergoing rapid change with a strong impact on the well-being of people living in lands surrounding its shores. The region is very varied and is one of the richest in the world in terms of biodiversity. Water is a limiting resource, not only 
for plants and animals, but also for humans. The geographic complexity of the region deeply impacted the cultural, social, economic and political history of Mediterranean populations, which in turn have left a strong imprint on its environment. Ecosystems and landscapes are mainly the product of ancient human use. Cultural features are strongly embedded in the landscape, and there is a sharp contrast in socio-economic features, particularly along the north-south gradient. It is very densely populated along the shores of the Mediterranean Sea. The south is experiencing considerable population growth, and imbalances are likely to increase in coming decades, making pressures on scarce water resources more and more acute.

So the Mediterranean basin is indeed a highly heterogeneous region. Natural phenomena interact in a very complex way. Human activity has strong feedback on climate at both local and regional scales. In socioeconomic terms there is a wide spectrum of interactions with natural impacts, from local to regional scales. They in turn impact on land use and land cover practices, and more generally on economic and social factors, such closing the loop.

The Mediterranean basin climate is also very sensitive to interactions with other parts of the world, for instance influences of the North Atlantic Oscillation (NAO), of the Indian Monsoon, and of dust transported from the Sahara to the Atlantic Ocean through the Mediterranean basin. This is also obviously true in socio-economic terms since the various Mediterranean nations are integrated in different international political and socio-economic structures, while 'globalisation' is strongly impacting the agriculture, industry and trading balances of most countries in the region.

While such complex interactions exist under 'stationary' climatic conditions it has been established that 'there are stronger evidences that most of the warming observed over the last 50 years is attributable to human activities' (IPCC, 2001 - see http://www.ipcc.ch). Such a climate tendency must have some impacts on the Mediterranean basin and neighbouring regions, such as sea level rise and modified rainfall patterns. It should be emphasised that, during the past 50 years, there has been evidence of global change and projected signatures onto the Mediterranean Sea. In this context and without careful planning, no long-term sustainable development can reasonably be envisioned in the Mediterranean basin. This is true at local, national, sub-regional and basin-wide levels.

Assessing the environmental status of the Mediterranean becomes a prerequisite - at least for the sake of knowledge and future implementation. This can be done following a nested methodological approach, going from simple to complex issues: 
- Assuming that no natural or human-induced changes are occurring, what is the environmental status of the region at large?

- Assuming no global change is occurring, what are the relative influences of both natural and anthropic pressures? Can we identify relevant indicators to monitor environmental and sustainable environment evolutions? Subsequently can we apply regulatory actions? What scenarios have to be used in running numerical models in order to predict future changes and anthropic action feedback?

- Assuming global change impacts on regional scales, what happens to the picture? Do we need additional scenarios? How can numerical models tackle physical mechanisms on a regional scale? What are the resulting uncertainties? Which major impacts are likely to be expected? Are there any additional and/or modified proactive solutions to apply?

Considerable efforts have been made to improve predictions about climate change. Nevertheless, the results still remain somehow uncertain, particularly at regional level in such a complex area. The fourth report of the ECLAT- 2 concerted action ${ }^{1}$ presents some key results in that regard. Nevertheless, the climate change features in the Mediterranean region remain poorly studied and documented so far, as it may appear when looking for results the 2001 IPCC reports. It is generally acknowledged that the region could be severely impacted by changes in climate, most notably by changes in the precipitation regime. Current model projections into the 21 st 'greenhouse gas' century tend to show quite a contrasting evolution between the northern and southern sides: intense warming and drying in the south; moderate warming and little variations, or even an increase of the precipitation in the north. Most likely, small alterations in water availability could have critical consequences at all natural and human levels in the region. Understanding such potential consequences of regional climate change therefore appears to be a critical issue. So, during the past years, a number of planning initiatives of Mediterranean regional significance have taken place aiming at evaluating its sensitivity to these impending threats of global change and promoting a regional research agenda.

Under the joint impetus of START ${ }^{2}$ and the $\mathrm{ENRICH}^{3}$ programme of the European Commission, a workshop was held in Toledo, Spain, from 25 to 28 September, 1996. Its objective was to set up a regional scientific agenda pinpointing the priorities to be refined by regional scientists in conjunction with the representatives of the international global change research programmes. A major conclusion was that a system approach was necessary to understand the many interactions in the region between the 
various intervening global change factors. Severe gaps appeared in such a regional integrated approach.

Taking such gaps into due consideration, some core actors of the Toledo workshop set up the RICAMARE project, ${ }^{4}$ which was endorsed at the end of 1998 by the European Commission as a concerted action and carried out from 1999 to 2001. RICAMARE was sponsored by two EC programmes (ENRICH and INCO-DC ${ }^{5}$, by START and to a less extent by some other national and international sources (such as, for instance ICTP ${ }^{6}, \mathrm{CIHEAM}^{7}$, FEEM, $\mathrm{CNES}^{8}, \mathrm{UCLM}^{9}$, IBERDROLA ${ }^{10}$ ). It focused on a few multidisciplinary, intersecting issues that deserve additional attention before they shape up into collaborative projects of regional importance. RICAMARE purposely linked natural and social scientists from the countries around the Mediterranean who are interested in tackling the inter-relationships between the natural and human environment in order to develop strategies for sustainable development in the region.

RICAMARE was organised into three 'activities': building a regional research agenda, setting up capacity building actions and leading outreach activities. These three activities focused on four major synergistic issues, two related to some key physical aspects, one to data collection, validation and assimilation, and one, held in Milan in 2001, to socio-economic aspects.

'Global change' usually refers to human-induced climate changes at the planetary level and associated impacts. In the Mediterranean basin, integrated impacts are due to anthropic 'local' activities which are superimposed on (or coupled to) the global change. Those impacts might then be amplified or accelerated. In any case a serious environmental assessment must take into account these two combined sources. Sorting out their individual actions, if possible, may be vital for local or regional decision-making processes. Indeed, different policies to mitigate adverse impacts have to be set up and adopted for 'local', 'regional' and 'global' change issues. The ambition of the authors of the present volume is to bring a modest contribution of their own to that highly challenging objective.

\section{NOTES}

1. ECLAT-2 - Applying climate scenarios for regional studies with particular references to the Mediterranean, Toulouse workshop report No. 4, Toulouse, France, 25-27 October 2000, edited by Serge Planton, Clair Hanson, David Viner and Michel Hoepffner.

2. START (global change system for analysis, research and training; http ://www.start.org) is a joint initiative of the three major international programmes addressing global change issues: IGBP, IHDP and WCRP.

3. European Network Research in Global Change, an initiative of the European Commission. 
4. The RICAMARE project was co-ordinated by Dr Gérard Begni and Pr J.M. Moreno, UCLM.

5. International Co-operation with Developing Countries, a programme of the DG Research of the European Commission.

6. International Centre for Theoretical Physics (Trieste, Italy).

7. French acronym of international centre for high agronomic studies.

8. CNES is the French space agency.

9. University of Castilla-la Mancha, located in Toledo, Spain.

10. IBERDROLA is a major Spanish private company. 
Carlo Giupponi and Mordechai Shechter - 9781781950258 Downloaded from PubFactory at 04/26/2023 03:24:49PM 